\title{
Classification of Extrapulmonary Manifestations Due to Mycoplasma pneumoniae Infection on the Basis of Possible Pathogenesis
}

\author{
Mitsuo Narita * \\ Department of Pediatrics, Sapporo Tokushukai Hospital, Sapporo, Japan
}

The list of extrapulmonary manifestations due to Mycoplasma pneumoniae infection can be classified according to the following three possible mechanisms derived from the established biological activity of $M$. pneumoniae; (1) a direct type in which the bacterium is present at the site of inflammation and local inflammatory cytokines induced by the bacterium play an important role (2) an indirect type in which the bacterium is not present at the site of inflammation and immune modulations, such as autoimmunity or formation of immune complexes, play an important role, and (3) a vascular occlusion type in which obstruction of blood flow induced either directly or indirectly

OPEN ACCESS

Edited by: Cécile Bébéar, University of Bordeaux, France

Reviewed by:

Patrick M. Meyer Sauteur, University Children's Hospital Zurich,

Switzerland

Thomas Prescott Atkinson, University of Alabama at Birmingham,

USA

*Correspondence: Mitsuo Narita naritamy@d5.dion.ne.jp

Specialty section: This article was submitted to Infectious Diseases,

a section of the journal

Frontiers in Microbiology

Received: 19 November 2015 Accepted: 11 January 2016 Published: 28 January 2016

Citation:

Narita M (2016) Classification of Extrapulmonary Manifestations Due to Mycoplasma pneumoniae Infection on the Basis of Possible Pathogenesis.

Front. Microbiol. 7:23.

doi: 10.3389/fmicb.2016.00023 by the bacterium plays an important role. Recent studies concerning extrapulmonary manifestations have prompted the author to upgrade the list, including cardiac and aortic thrombi as cardiovascular manifestations; erythema nodosum, cutaneous leukocytoclastic vasculitis, and subcorneal pustular dermatosis as dermatological manifestations; acute cerebellar ataxia, opsoclonus-myoclonus syndrome, and thalamic necrosis as neurological manifestations; pulmonary embolism as a respiratory system manifestation; and renal artery embolism as a urogenital tract manifestation. Continuing nosological confusion on M. pneumoniae-induced mucositis (without skin lesions), which may be called $M$. pneumoniae-associated mucositis or $M$. pneumoniae-induced rash and mucositis separately from Stevens-Johnson syndrome, is argued in the dermatological manifestations. Serological methods are recommended for diagnosis because pneumonia or respiratory symptoms are often minimal or even absent in extrapulmonary manifestations due to $M$. pneumoniae infection. Concomitant use of immunomodulators, such as corticosteroids or immunoglobulins with antibiotics effective against $M$. pneumoniae, can be considered as treatment modalities for most severe cases, such as encephalitis. Further studies would be necessary to construct a comprehensive therapeutic strategy, covering microbiology (antibiotics), immunology (immunomodulators), and hematology (anticoagulants). The possible influence of the emergence of macrolide-resistant $M$. pneumoniae on extrapulmonary manifestations, which can be considered of limited clinical threat in Japan where the resistant rate has currently decreased, is discussed on the basis of unique biological characteristics of M. pneumoniae, the smallest self-replicating organism.

Keywords: pneumonia, cytokine, interleukin-18, autoimmunity, immune complex, vasculitis, vasculopathy, macrolide resistance 


\section{INTRODUCTION}

Mycoplasma pneumoniae has been known to cause a wide variety of extrapulmonary diseases, including several organs of the human body, but its pathomechanisms remain largely unknown. Following is a list of extrapulmonary manifestations due to $M$. pneumoniae infection classified according to the three possible pathomechanisms: (1) a direct type in which the bacterium is present at the site of inflammation and local inflammatory cytokines induced by the bacterium play an important role (2) an indirect type in which the bacterium is not present at the site of inflammation and immune modulations, such as autoimmunity or formation of immune complexes, play an important role (3) a vascular occlusion type in which obstruction of blood flow induced either directly or indirectly by the bacterium plays an important role (Narita, 2009, 2010, 2011a). Several years have passed since the initial list was presented and recent studies have prompted the author to upgrade the list (Table 1). While constructing the list, according to the primary policy (Narita, 2009, 2010, 2011a), diseases that can reasonably be considered true extrapulmonary manifestations due to $M$. pneumoniae infection on the basis of established biological ability of M. pneumoniae were preferentially selected, although it is hard to prove exactly the causal relation between $M$. pneumoniae infection and the development of diseases in indirect type manifestations. Because more recent studies are preferentially cited in this review, many fundamentally important matters are not mentioned here; frequent absence of pneumonia in the direct type manifestations, cold agglutinins in hematological manifestations, autoantibodies in neurological manifestations, and immunodeficiency in arthritis, among others. Also refer to the previous reviews (Narita, 2009, 2010, 2011a) for further discussions on those matters.

\section{Cardiovascular System Manifestations}

Cardiac thrombi in the left atrium (Bakshi et al., 2006), in the right ventricle (Nagashima et al., 2010), and an aortic thrombus (Flateau et al., 2013) have been reported as the vascular occlusion type manifestation of the cardiovascular system. Interestingly, all the cases revealed the existence of some type of antiphospholipid antibodies in the blood, such as anticardiolipin antibody and lupus anticoagulant, which can be raised during $M$. pneumoniae infection through molecular mimicry between $M$. pneumoniae cell components and human phospholipids (Narita, 2011a). A mechanism speculating about how these antibodies modulate the coagulation system leading to thrombosis is incompletely understood. These antibodies in most cases disappear during convalescence and the hypercoagulable state does not last for many months. Pneumonia may or may not be present. A short comprehensive review on this topic is presented in (Flateau et al., 2013).

While Kawasaki disease associated with M. pneumoniae infection is not unusual in Japan (Narita, 2010, 2011a) and may be found in Korea (Lee et al., 2011), the disease association is rarely reported outside Asia; however, few recent cases were observed in Italy (Vitale et al., 2010) and the United States (Ebrahim et al., 2011). Considering that pneumonia is not a hallmark of mycoplasmal infection, further surveys outside Asia would more precisely delineate the occurrence of this disease association among different ethnic groups. A short analytical review on this topic can be found in (Lee et al., 2011).

A recent report from China on myocardial damages during M. pneumoniae infection presented a little evidence for some type of immune modulation by M. pneumoniae (Fan et al., 2015).

\section{Dermatological Manifestations}

Erythema nodosum, which is considered to be an immunemediated disease, mainly affects young women $(<30$ years old) and is characterized clinically by tender erythematous nodules (diameter $>1 \mathrm{~cm}$ ) on lower legs and histologically by septal panniculitis (Cribier et al., 1998; Kakourou et al., 2001). While its frequency among mycoplasmal infections has been reported to be rather small, that is, in $3 / 27$ (11\%) patients with established etiology (Kakourou et al., 2001) or 1/32 (3.1\%) patients undergoing mycoplasmal serology testing (Cribier et al., 1998), increasing awareness of the disease association (Kano et al., 2007; Schalock and Dinulos, 2009; Shimizu et al., 2012) allows it to become a subject of specific reviews (Greco et al., 2015; Terraneo et al., 2015). This disease must be included in the indirect type manifestations. Pneumonia is infrequent in this disease.

Cutaneous leukocytoclastic vasculitis is a pathological entity of skin disease characterized histologically by a neutrophilic perivascular infiltrate and clinically by erythematous macropapular rash mainly on lower extremities; it resembles erythema nodosum but is less tender and smaller in size (Kakourou et al., 2001). Several cases of this disease have been reported in association with $M$. pneumoniae infection (Van Bever et al., 1992; Perez et al., 1997; Perez and Montes, 2002; Greco et al., 2007; Trčko et al., 2012; Lee et al., 2015; Terraneo et al., 2015). Interestingly the reported cases were almost always accompanied by other organ involvement such as glomerulonephritis (Lee et al., 2015), arthritis (Perez et al., 1997; Lee et al., 2015), or arthralgia (Trčko et al., 2012), retinal vasculitis (Greco et al., 2007), encephalitis (Perez and Montes, 2002), and acute respiratory distress syndrome, erythema multiforme, and pancreatitis (Van Bever et al., 1992). Because circulating immune complexes are considered to play a critical role in the pathogenesis of cutaneous leukocytoclastic vasculitis (Van Bever et al., 1992; Perez and Montes, 2002; Trčko et al., 2012), this must be a partial manifestation of systemic vasculitic disease as a consequence of immune dysregulation elicited by an M. pneumoniae infection. Pneumonia may or may not be present.

Nosological confusion still exists concerning the spectrum of skin and mucous membrane diseases, including Stevens-Johnson syndrome (SJS), Fuchs syndrome, toxic epidermal necrolysis, and erythema multiforme major (Schalock and Dinulos, 2009; Wetter and Camilleri, 2010; Kunimi et al., 2011; Meyer Sauteur et al., 2012; Canavan et al., 2015a; Vujic et al., 2015). It has been acknowledged that $M$. pneumoniae is the most frequent infectious agent identified in "typical SJS" (Schalock and Dinulos, 2009; Wetter and Camilleri, 2010; Kunimi et al., 2011), presenting 
TABLE 1 | Extrapulmonary manifestations due to $M$. pneumoniae infection classified according to the involved pathomechanisms.

\begin{tabular}{|c|c|c|c|c|}
\hline Manifestations & Direct type $^{a}$ & Indirect type $e^{b}$ & $\begin{array}{l}\text { Vascular occlusion } \\
\text { type }^{c}\end{array}$ & Undetermined $^{d}$ \\
\hline Cardiovascular system & $\begin{array}{l}\text { Pericarditis, } \\
\text { Endocarditis }\end{array}$ & Myocarditis, Kawasaki disease & $\begin{array}{l}\text { Cardiac thrombus, } \\
\underline{\text { Aortic thrombus }}\end{array}$ & \\
\hline Dermatological & & $\begin{array}{l}\text { Erythema multiforme, Urticaria, } \\
\text { Anaphylactoid purpura, EN, } \underline{\text { CLV }} \text {, } \\
\underline{\text { SJS }}, \underline{\text { MPAM }} \underline{\text { SPD }}\end{array}$ & & \\
\hline Digestive organ & $\begin{array}{l}\text { Early onset } \\
\text { hepatitis }\end{array}$ & Late onset hepatitis & Pancreatitis & \\
\hline $\begin{array}{l}\text { Hematological/ } \\
\text { Hematopoietic system }\end{array}$ & & $\begin{array}{l}\text { Autoimmune hemolytic anemia, } \\
\text { Hemophagocytic syndrome, } \\
\text { Thrombocytopenic purpura, } \\
\text { Infectious mononucleosis }\end{array}$ & $\begin{array}{l}\text { Disseminated } \\
\text { intravascular } \\
\text { coagulation, Splenic } \\
\text { infarct }\end{array}$ & \\
\hline $\begin{array}{l}\text { Musculoskeletal } \\
\text { system }\end{array}$ & Arthritis & & & Rhabdomyolysis \\
\hline Neurological & $\begin{array}{l}\text { Early onset } \\
\text { encephalitis, Early } \\
\text { onset myelitis, } \\
\text { Aseptic } \\
\text { meningitis }\end{array}$ & $\begin{array}{l}\text { Late onset encephalitis, Late onset } \\
\text { myelitis, Guillain-Barré syndrome, } \\
\text { Cranial/peripheral neuropathies, } \\
\text { Cerebellitis, Acute cerebellar ataxia, } \\
\text { Opsoclonus-myoclonus syndrome }\end{array}$ & $\begin{array}{l}\text { Stroke, Psychological } \\
\text { disorders, Striatal } \\
\text { necrosis, Thalamic } \\
\underline{\text { necrosis }}\end{array}$ & $\begin{array}{l}\text { Acute } \\
\text { disseminated } \\
\text { encephalomyelitis }\end{array}$ \\
\hline Respiratory system & & & Pulmonary embolism & \\
\hline Sensory organ & Otitis media & Conjunctivitis, Iritis, Uveitis & Sudden hearing loss & \\
\hline Urogenital tract & & Glomerulonephritis, IgA nephropathy & $\begin{array}{l}\text { Priapism, } \\
\text { Renal artery embolism }\end{array}$ & \\
\hline
\end{tabular}

${ }^{a} M$. pneumoniae causes inflammation at the local site through the induction of cytokines.

${ }^{b} M$. pneumoniae causes inflammation through immune modulation such as autoimmunity, or formation of immune complexes.

${ }^{c} M$. pneumoniae causes vasculitic and/or thrombotic vascular occlusion with or without systemic hypercoagulable state.

dEither or all of the above three types of mechanisms may be involved.

Underlines indicate diseases which are newly included in the panel or grouped into a different type of manifestation from the previous list (Narita, 2010).

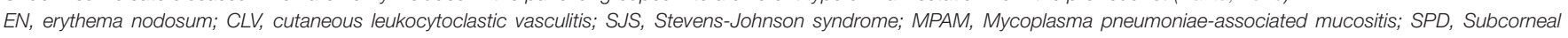
pustular dermatosis.

with fever, conjunctivitis, stomatitis, generalized, often bullous cutaneous lesions (macules and flat atypical target lesions) involving $<10 \%$ of body surface, and severe morbidity and substantial mortality (Meyer Sauteur et al., 2012). Moreover, an outbreak of M. pneumoniae-associated "typical SJS" was recently reported (Olson et al., 2015). In parallel with this, presence of another distinct form of diseases mimicking SJS and without skin lesions, is widely noticed and is often called as "atypical SJS" or "incomplete SJS." Although universal agreement has not yet been established, those can be a distinct entity and are presently called $M$. pneumoniae-associated mucositis (Schalock and Dinulos, 2009; Meyer Sauteur et al., 2012; Vujic et al., 2015) or M. pneumoniae-induced rash and mucositis (Canavan et al., 2015a,b; Norton, 2015). From a clinical point of view, $M$. pneumoniae-associated mucous membrane diseases, irrespective of whether they are "typical" or "atypical," have been considered less severe, often sensitive to corticosteroid therapy, and with fundamentally good prognosis when compared with drug-induced diseases (Schalock and Dinulos, 2009; Wetter and Camilleri, 2010; Kunimi et al., 2011; Meyer Sauteur et al., 2012; Canavan et al., 2015a; Vujic et al., 2015). These factors may be important especially for physicians in treating this spectrum of diseases, because to distinguish M. pneumoniaeassociated diseases from drug-induced diseases early in the course allows them to predict the better prognosis for the M. pneumoniae-associated diseases. One factor which favors the M. pneumoniae-associated rather than the drug-induced diseases is younger age as it occurs more often in children and younger adults (Wetter and Camilleri, 2010; Kunimi et al., 2011; Canavan et al., 2015b; Norton, 2015). Meanwhile, three independent reports have similarly pointed out that severe ocular lesions were fairly frequent in the M. pneumoniae-associated diseases compared to the drug-induced diseases (Wetter and Camilleri, 2010; Kunimi et al., 2011; Olson et al., 2015), and might be an additional diagnostic indicator. Regarding pathogenesis, immunological mechanisms such as autoimmunity and immune complex-mediated vascular injury have been suspected irrespective of whether it is $M$. pneumoniae-associated 
or not. Some authors have speculated that the synergistic effects of $M$. pneumoniae infection (and ensuing immune dysregulation) and drug exposure are important factors in developing mucous lesions (Schalock and Dinulos, 2009; Shimizu et al., 2012; Kurata et al., 2016). The reason why the $M$. pneumoniae-associated lesions are confined to the mucous membranes remains unclear. Lastly, the fact that $M$. pneumoniae was isolated from skin blister fluid on at least two independent occasions must not be ignored, which suggests the possibility of a direct type mechanism (Lyell et al., 1967; Meseguer et al., 1986). Because M. pneumoniae can never infect squamous cell epithelium, hematogenous transfer of $M$. pneumoniae from the respiratory tract to the skin might generate the inflammatory bullous lesions through the induction of cytokines.

Although very rare, subcorneal pustular dermatosis must be associated with M. pneumoniae infection (Lombart, 2014; Bohelay et al., 2015), which can be considered an indirect manifestation.

\section{Digestive Organ Manifestations}

A report on liver dysfunction in adults further substantiated the premise that hepatitis can be grouped into the two categories, consisting of the early- and late-onset types, the former being reported to occur at a median of 4 days from the respiratory onset and the latter at 13 days (Shin et al., 2012). Molecular mimicry between mycoplasmal cell components and sialooligosaccharides displayed on hepatic cell surfaces was speculated as a pathomechanism for the late-onset type. Another recent report on hepatic damages during $M$. pneumoniae infection also presented a little evidence for some type of immune modulation by M. pneumoniae (Fan et al., 2015).

A case report on necrotizing pancreatitis (Yang et al., 2015) favors vascular occlusion as the etiology of acute pancreatitis associated with $M$. pneumoniae infection as previously suggested (Van Bever et al., 1992; Narita, 2010).

\section{Hematological/Hematopoietic System Manifestations}

A case of splenic artery embolism was reported as a vascular occlusion type manifestation (Flateau et al., 2013).

\section{Musculoskeletal System Manifestations}

We have reported that production of tumor necrosis factor$\alpha$ might play a role in the pathogenesis of rhabdomyolysis associated with M. pneumoniae infection (Oishi et al., 2012).

\section{Neurological Manifestations}

Opsoclonus-myoclonus syndrome is a rare neurological disorder characterized by involuntary, irregular, and multidirectional eye movements with myoclonus predominantly affecting the head and trunk and signs of cerebellar ataxia, especially the inability to stand and walk. While this syndrome has been known to occur in association with neuroblastomas in infants between 6 and 36 months and with various types of malignant tumors in adults, infectious etiologies are also known. Recent studies on this syndrome in association with M. pneumoniae infection in children (Huber et al., 2010; Shiihara and Takahashi, 2010) as well as in adults (Mesraoua et al., 2011; Nunes et al., 2011), which have suggested immune pathogenesis, have made it reasonable to assume that this syndrome can be included in the indirect type manifestations.

In addition to striatal necrosis (Narita, 2009, 2011a), brain diseases, in which characteristic bilateral lesions are observed on neuroimaging, have not infrequently been reported in association with $M$. pneumoniae infection. The affected areas include the pons (Perez and Montes, 2002), thalamus (Ashtekar et al., 2003), basal ganglia, and thalamus (Fusco et al., 2010), striatum and brain stem (Bae et al., 2011), and splenium of corpus callosum (Shibuya et al., 2012). Vasculitic necrosis is considered a presumptive etiology in some (Perez and Montes, 2002; Ashtekar et al., 2003), and immune pathogenesis is considered in others (Fusco et al., 2010; Bae et al., 2011). In this context, the clinical picture of a case presented in Perez and Montes (2002) fairly resembles that of acute necrotizing encephalopathy, which favors vasculitic etiology (Narita, 2002), whereas the intrathecal production of interleukins- 6 and -8 was found in the patients with striatal necrosis (Yuan et al., 2015), as reported in the cases of encephalitis (Narita et al., 2005), which favors immune pathogenesis. A recent comprehensive study suggested that these manifestations are not peculiar but is a common form of encephalitis in children (Al-Zaidy et al., 2015). Representative of these diseases, both striatal and thalamic necrosis are included in the list of this review as vascular occlusion type manifestations. Meanwhile, some nosological alterations might be necessary concerning the use of the term "necrosis" for the fundamentally benign, reversible lesions, which are a characteristic of $M$. pneumoniae infection (Fusco et al., 2010).

Concerning disseminated encephalomyelitis, a recent paper reported that the genome of $M$. pneumoniae was detected in cerebrospinal fluid, suggesting the direct type mechanism (Matsumoto et al., 2009), whereas another paper reported a dramatic improvement after plasma exchange, suggesting the indirect type mechanism leading to vasculopathy (Gupta et al., 2009). The aforementioned study has suggested that a single etiology cannot explain the pathogenesis of acute disseminated encephalomyelitis (Al-Zaidy et al., 2015). In addition, the study also suggested that the classification for encephalitis can also be applied to transverse myelitis (the early onset, direct type or the late onset, indirect type).

Two cases of transient Parkinsonism in association with M. pneumoniae infections have recently been reported (Tay et al., 2014). With more attention given to $M$. pneumoniae infections even in the absence of respiratory symptoms, more cases of $M$. pneumoniae infection-associated psychological disorders would be diagnosed especially when it is transient and occurs in children or young adults.

Cerebellitis has been constantly reported as part of a disease involving multiple parts of the brain (Christo et al., 2010; Bae et al., 2011; Meyer Sauteur et al., 2014a) or as an isolated disease (Shkalim et al., 2009; Simpkins et al., 2012; Schmucker et al., 2014). Immune-mediated pathogenesis has been advocated for cerebellitis and is most likely an indirect type manifestation. The fact that lymphocytic infiltration was found in the cerebellar tissue in the late onset case (Simpkins et al., 
2012) is of some interest because the neutrophilic infiltration has typically been found in the cerebral tissues of early onset cases (Bruch et al., 2001; Stamm et al., 2008). Implication of these observations on pathogenesis remains unclear, but accumulation of histological investigations should provide us with clues for further understanding of the pathogenesis of neurological manifestations.

In acute cerebellar ataxia the evidence of neural inflammation is apparently absent and an immune-mediated pathogenesis has been suggested (Cimolai et al., 1994); this has been added to the list separately from cerebellitis.

Although it is still premature to conclude that it is a true manifestation of $M$. pneumoniae infection, a peculiar and rather pathologically identified disease entity called "mycoplasmal cerebral vasculopathy" has recently been suggested (Zu-Rhein et al., 2007; Ferreira, 2011; Rhodes et al., 2011). Because of its slowly progressive clinical course that occurs over several years with episodic encephalopathy and movement disorders, it is hard to determine whether the disease constitutes a distinct clinical entity. Nevertheless, the findings that M. pneumoniae antigens were found in the cytoplasm of brain microvascular endothelial cells as well as in microvascular lumina by histological investigations are highly interesting. This appears to further support the ability of hematogenous transfer of M. pneumoniae to the brain and to elicit vasculitis or vasculopathy at those local sites.

At the end of this section, a schematic presentation is shown in Figure 1 for the neurological manifestations due to M. pneumoniae infection classified according to the possible pathomechanisms, which can be perplexing and sometimes overlapping. This figure suggests one possibility and is amenable to improvement by future studies. More information on neurological manifestations is presented in recent studies (Bitnun and Richardson, 2010; Meyer Sauteur et al., 2014b).

\section{Respiratory System Manifestations}

A few cases of pulmonary embolism have been reported in association with $M$. pneumoniae infection (Sterner and Biberfeld, 1969; Brown et al., 2008; Graw-Panzer et al., 2009). Production of antiphospholipid antibodies has been shown to be an underlying mechanism for thrombus formation (Brown et al., 2008; GrawPanzer et al., 2009).

\section{Urogenital Tract Manifestations}

Each case of glomerulonephritis (Shimizu et al., 2012) or glomerulonephritis with interstitial nephritis (Lee et al., 2015) was recently reported along with multiple skin lesions mentioned in the previous dermatological section. The genome of $M$. pneumoniae was detected by polymerase chain reaction in a serum sample from a patient with glomerulonephritis (Chen et al., 2015), which further substantiated the assumption that circulating immune complexes containing mycoplasmal cell components are probably involved in the pathogenesis.

A case of renal artery embolism was reported in a patient with multiple embolisms (Flateau et al., 2013).

A new case of pediatric priapism was recently reported (Jacobs et al., 2015), which substantiated that this condition

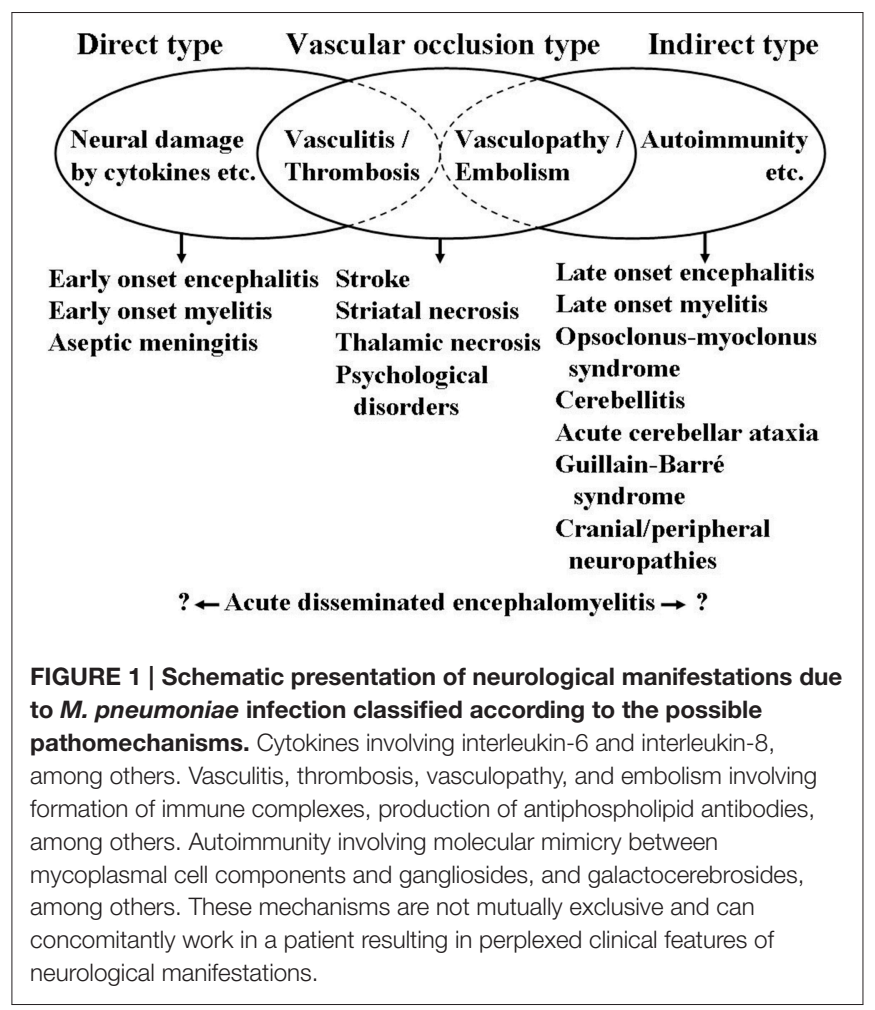

can be an extremely rare but reasonable vascular occlusion type manifestation.

\section{DIAGNOSIS OF EXTRAPULMONARY MANIFESTATIONS DUE TO M. pneumoniae INFECTIONS}

Since the primary site of infection and subsequent propagation of $M$. pneumoniae is restricted to the ciliated epithelium of the lower respiratory tract, any existing bacterial cells cannot be transferred to the upper respiratory tract in the absence of strong cough. In this context, as repeatedly mentioned in this and the previous reviews (Narita, 2009, 2010, 2011a), extrapulmonary manifestations due to $M$. pneumoniae infection often occur in the absence of pneumonia or even in the absence of respiratory symptoms. For this reason, molecular detection or culture methods using routine clinical samples obtained from the upper respiratory tract (such as pharyngeal swabs) are not always adequate for diagnosing extrapulmonary manifestations. Therefore, the diagnosis should be done by serological methods, which usually requires obtaining a second serum sample. On a few special occasions, molecular detection methods may be applied for non-respiratory samples, such as cerebrospinal fluid for encephalitis. For cases with abundant cough, point-of-care tests, which have recently been developed in Japan and include the loop-mediated isothermal amplification method (Kakuya et al., 2014; Petrone et al., 2015) or the antigen detection method (Miyashita et al., 2015b), should be used 
because they may help in rapid diagnosis during the acute phase.

\section{TREATMENT OF EXTRAPULMONARY MANIFESTATIONS DUE TO M. pneumoniae INFECTION}

There is no doubt that aberrant host immune responses play a critical role in the development of extrapulmonary manifestations due to M. pneumoniae infections. Therefore, immunomodulators, such as corticosteroids or immunoglobulins, should be beneficial for the most severe cases, such as encephalitis or SJS. Moreover, anticoagulation therapy should be highly promising for the vascular occlusion type manifestations. In any of the cases, antibiotics effective against M. pneumoniae must be used concomitantly to reduce the amount of $M$. pneumoniae cells in the respiratory tract; this consequently results in the reduction of excessive antigenic stimuli. Larger studies would be necessary to construct the comprehensive therapeutic strategy covering microbiology (antibiotics), immunology (immunomodulators), and hematology (anticoagulants).

\section{POSSIBLE INFLUENCE OF THE EMERGENCE OF MACROLIDE-RESISTANT M. pneumoniae ON EXTRAPULMONARY MANIFESTATIONS}

Since 2000, when the first case of pneumonia due to macrolideresistant M. pneumoniae was diagnosed in Japan (Okazaki et al., 2001), macrolide resistance has grown to be a significant problem in some countries, particularly in eastern Asia. A few cases of extrapulmonary manifestations due to macrolide-resistant M. pneumoniae have been reported (Atkinson et al., 2011; Koga et al., 2012; Oishi et al., 2012; Shen et al., 2013; Zhou et al., 2014). While the studies from China have reported that a substantial number of complications (most frequently liver and myocardial dysfunctions) occurred in patients infected by resistant strains (Shen et al., 2013; Zhou et al., 2014), no appreciable increase in the number of extrapulmonary manifestations has been observed

\section{REFERENCES}

Al-Zaidy, S. A., MacGregor, D., Mahant, S., Richardson, S. E., and Bitnun, A. (2015). Neurological complications of PCR-proven $M$. pneumoniae infections in children: prodromal illness duration may reflect pathogenetic mechanism. Clin. Infect. Dis. 61, 1092-1098. doi: 10.1093/cid/civ473

Ashtekar, C. S., Jaspan, T., Thomas, D., Weston, V., Gayatri, N. A., and Whitehouse, W. P. (2003). Acute bilateral thalamic necrosis in a child with Mycoplasma pneumoniae. Dev. Med. Child Neurol. 45, 634-637. doi: 10.1111/j.1469-8749.2003.tb00969.x

Atkinson, T. P., Boppana, S., Theos, A., Clements, L. S., Xiao, L., and Waites, K. (2011). Stevens-Johnson syndrome in a boy with macrolideresistant Mycoplasma pneumoniae pneumonia. Pediatrics 127, e1605-e1609. doi: 10.1542/peds.2010-2624

Bae, J.-W., Kim, H.-J., Chang, G. Y., and Kim, E.-J. (2011). Combined striatum, brain stem, and optic nerve involvement due to Mycoplasma pneumoniae in an ambulatory child. Case Rep. Neurol. 3, 109-112. doi: 10.1159/000328836 in Japan in conjunction with a significant increase in the number of pneumonia patients infected by the resistant strains. This must be in part due to the impairment of the growth ability of resistant strains of $M$. pneumoniae when compared with the sensitive strains (Ohya et al., 2009, 2010; Pauchant et al., 2009) Some reasons for this are described in the following paragraphs.

M. pneumoniae is one of the smallest self-replicating organisms and has many peculiar biological characteristics. First of all, the most important characteristic associated with drug resistance is that extrinsic genes, such as plasmids or transposons, do not function within $M$. pneumoniae cells under natural conditions (Bébéar and Pereyre, 2005). Consequently, the resistant mechanism of $M$. pneumoniae is exclusively due to a point mutation in the domain $\mathrm{V}$ of $23 \mathrm{~S}$ rRNA. Second, since M. pneumoniae has only one operon for constructing ribosomes (Himmelreich et al., 1996), the resistant strains that harbor a point mutation within their ribosome genes are exclusively mutants of ribosomes. Therefore, they suffer from less efficient protein synthesis and are deficient in growth ability (Narita, 2011b). In fact, no excessive morbidity has been observed particularly ascribed to the drug resistance in the reported cases (Atkinson et al., 2011; Koga et al., 2012; Oishi et al., 2012). In addition to that, serum levels of IL-18, which represent disease activity of M. pneumoniae infection (Narita et al., 2000; Tanaka et al., 2002; Oishi et al., 2011; Miyashita et al., 2015a), were rather lower in patients with pneumonia infected by the resistant strains than in patients infected by the sensitive strains (Matsuda et al., 2013). Taken together, the emergence of macrolide-resistant $M$. pneumoniae must not be a significant clinical threat concerning extrapulmonary manifestations of M. pneumoniae infection at least in Japan, where the resistant rate has fundamentally been decreasing according to the current data obtained from 2013 to 2015 (presented at domestic Japanese meetings).

\section{AUTHOR CONTRIBUTIONS}

The author confirms being the sole contributor of this work and approved it for publication.

Bakshi, M., Khemani, C., Vishwanathan, V., Anand, R. K., and Khubchandani, R. P. (2006). Mycoplasma pneumonia with antiphospholipid antibodies and a cardiac thrombus. Lupus 15, 105-106. doi: 10.1191/0961203306lu2258cr

Bébéar, C. M., and Pereyre, S. (2005). Mechanisms of drug resistance in Mycoplasma pneumoniae. Curr. Drug Targets 5, 263-271. doi: 10.2174/1568005054880109

Bitnun, A., and Richardson, S. E. (2010). Mycoplasma pneumoniae: innocent bystander or a true cause of central nervous system disease? Curr. Infect. Dis. Rep. 12, 282-290. doi: 10.1007/s11908-010-0105-4

Bohelay, G., Duong, T. A., Ortonne, N., Chosidow, O., and Valeyrie-Allanore, L. (2015). Subcorneal pustular dermatosis triggered by Mycoplasma pneumoniae infection: a rare clinical association. J. Eur. Acad. Dermatol. Venereol. 29, 1022-1025. doi: 10.1111/jdv.12446

Brown, S. M., Padley, S., Bush, A., Cummins, D., Davidson, S., and Buchdahl, R. (2008). Mycoplasma pneumonia and pulmonary embolism in a child due to acquired prothrombotic factors. Pediatr. Pulmonol. 43, 200-202. doi: 10.1002/ppul.20739 
Bruch, L. A., Jefferson, R. J., Pike, M. G., Gould, S. J., and Squier, W. (2001). Mycoplasma pneumoniae infection, meningoencephalitis, and hemophagocytosis. Pediatr. Neurol. 25, 67-70. doi: 10.1016/S08878994(01)00274-0

Canavan, T. N., Mathes, E. F., Frieden, I. J., and Shinkai, K. (2015b). Reply to: "Diagnosing Mycoplasma pneumoniae-induced rash and mucositis (MIRM) in the emergency room." J. Am. Acad. Dermatol. 73, e69. doi: 10.1016/j.jaad.2015.04.046

Canavan, T. N., Mathes, E. F., Frieden, I., and Shinkai, K. (2015a). Mycoplasma pneumoniae-induced rash and mucositis as a syndrome distinct from Stevens-Johnson syndrome and erythema multiforme: a systematic review. J. Am. Acad. Dermatol. 72, 239-245. doi: 10.1016/j.jaad.2014. 06.026

Chen, X., Xu, W., Du, J., and Wang, H. (2015). Acute postinfectious glomerulonephritis with a large number of crescents caused by Mycoplasma pneumoniae. Indian J. Pathol. Microbiol. 58, 374-376. doi: 10.4103/03774929.162907

Christo, P. P., da Silva, J. S. P., Werneck, I. V., and Dias, S. L. (2010). Rhombencephalitis possibly caused by Mycoplasma pneumoniae. Arq. Neuropsiquiatr. 68, 656-658. doi: 10.1590/S0004-282X20100004 00035

Cimolai, N., Mah, D., and Roland, E. (1994). Anticentriolar autoantibodies in children with central nervous system manifestations of Mycoplasma pneumoniae infection. J. Neurol. Neurosurg. Psychiatry 57, 638-639. doi: 10.1136/jnnp.57.5.638

Cribier, B., Caille, A., Heid, E., and Grosshans, E. (1998). Erythema nodosum and associated diseases. A study of 129 cases. Int. J. Dermatol. 37, 667-672. doi: 10.1046/j.1365-4362.1998.00316.x

Ebrahim, M., Gabay, M., and Rivas-Chacon, R. F. (2011). Evidence of acute Mycoplasma infection in a patient with incomplete and atypical Kawasaki disease: a case report. Case Rep. Med. 2011:606920. doi: 10.1155/2011/606920

Fan, Q., Meng, J., Li, P., Liu, Z., Sun, Y., and Yan, P. (2015). Pathogenesis and association of Mycoplasma pneumoniae infection with cardiac and hepatic damage. Microbiol. Immunol. 59, 375-380. doi: 10.1111/1348-0421.12267

Ferreira, J. (2011). Correspondence regarding: a novel cerebral microangiopathy with endothelial cell atypia and multifocal white matter lesions: a direct mycoplasmal infection? J. Neuropathol. Exp. Neurol. 70, 236-237. doi: 10.1097/NEN.0b013e31820dd7ae

Flateau, C., Asfalou, I., Deman, A.-L., Ficko, C., Andriamanantena, D., Fontan, E., et al. (2013). Aortic thrombus and multiple embolisms during a Mycoplasma pneumoniae infection. Infection 41, 867-873. doi: 10.1007/s15010-013-0475-2

Fusco, C., Bonini, E., Soncini, G., Frattini, D., Giovannini, S., and Giustina, E. D. (2010). Transient basal ganglia and thalamic involvement following Mycoplasma pneumoniae infection associated with antiganglioside antibodies. J. Child Neurol. 25, 1029-1033. doi: 10.1177/0883073809355823

Graw-Panzer, K. D., Verma, S., Rao, S., Miller, S. T., and Lee, H. (2009). Venous thrombosis and pulmonary embolism in a child with pneumonia due to Mycoplasma pneumoniae. J. Natl. Med. Assoc. 101, 956-958. doi: 10.1016/S0027-9684(15)31045-2

Greco, F., Catania, R., Pira, A. L., Saporito, M., Scalora, L., Aguglia, M. G., et al. (2015). Erythema nodosum and Mycoplasma pneumoniae infections in childhood: further observations in two patients and a literature review. J. Clin. Med. Res. 7, 274-277. doi: 10.14740/jocmr2011w

Greco, F., Sorge, A., Salvo, V., and Sorge, G. (2007). Cutaneous vasculitis associated with Mycoplasma pneumoniae infection: case report and literature review. Clin. Pediatr. (Phila). 46, 451-453. doi: 10.1177/0009922806298638

Gupta, A., Kimber, T., Crompton, J. L., and Karagiannis, A. (2009). Acute disseminated encephalomyelitis secondary to Mycoplasma pneumoniae. Intern. Med. J. 39, 68-69. doi: 10.1111/j.1445-5994.2008.01777.x

Himmelreich, R., Hilbert, H., Plagens, H., Pirkl, E., Li, B.-C., and Herrmann, R. (1996). Complete sequence analysis of the genome of the bacterium Mycoplasma pneumoniae. Nucleic Acids Res. 24, 4420-4449. doi: 10.1093/nar/24.22.4420

Huber, B. M., Strozzi, S., Steinlin, M., Aebi, C., and Fluri, S. (2010). Mycoplasma pneumoniae associated opsoclonus-myoclonus syndrome in three cases. Eur. J. Pediatr. 169, 441-445. doi: 10.1007/s00431-009-1048-3

Jacobs, M., Lo, M. D., and Lendvay, T. S. (2015). Painless pediatric priapism and cough. Pediatr. Emerg. Care 31, 36-38. doi: 10.1097/PEC.0000000000000206
Kakourou, T., Drosatou, P., Psychou, F., Aroni, K., and Nicolaidou, P. (2001) Erythema nodosum in children: a prospective study. J. Am. Acad. Dermatol. 44, 17-21. doi: 10.1067/mjd.2001.110877

Kakuya, F., Kinebuchi, T., Fujiyasu, H., Tanaka, R., and Kano, H. (2014). Genetic point-of-care diagnosis of Mycoplasma pneumoniae infection using LAMP assay. Pediatr. Int. 56, 547-552. doi: 10.1111/ped.12327

Kano, Y., Mitsuyama, Y., Hirahara, K., and Shiohara, T. (2007). Mycoplasma pneumoniae infection-induced erythema nodosum, anaphylactoid purpura, and acute urticaria in 3 people in a single family. J. Am. Acad. Dermatol. 57(2 Suppl.), S33-S35. doi: 10.1016/j.jaad.2005.08.027

Koga, S., Ishiwada, N., Honda, Y., Okunushi, T., Hishiki, H., Ouchi, K., et al. (2012). A case of meningoencephalitis associated with macrolideresistant Mycoplasma pneumoniae infection. Pediatr. Int. 54, 724-726. doi: 10.1111/j.1442-200X.2012.03588.x

Kunimi, Y., Hirata, Y., Aihara, M., Yamane, Y., and Ikezawa, Z. (2011). Statistical analysis of Stevens-Johnson syndrome caused by Mycoplasma pneumoniae infection in Japan. Allergol. Int. 60, 525-532. doi: 10.2332/allergolint.11-OA0309

Kurata, M., Kano, Y., Sato, Y., Hirahara, K., and Shiohara, T. (2016). Synergistic effects of Mycoplasma pneumoniae infection and drug reaction on the development of atypical Stevens-Johnson syndrome in adults. Acta Derm. Venereol. 96, 111-113. doi: 10.2340/00015555-2180

Lee, H., Moon, K. C., and Kim, S. (2015). Cutaneous vasculitis and renal involvement in Mycoplasma pneumoniae infection. Korean J. Intern. Med. 30, 402-405. doi: 10.3904/kjim.2015.30.3.402

Lee, M. N., Cha, J. H., Ahn, H. M., Yoo, J. H., Kim, H. S., Sohn, S., et al. (2011). Mycoplasma pneumoniae infection in patients with Kawasaki disease. Korean J. Pediatr. 54, 123-127. doi: 10.3345/kjp.2011.54.3.123

Lombart, F. (2014). Subcorneal pustular dermatosis associated with Mycoplasma pneumoniae infection. J. Am. Acad. Dermatol. 71, e85-e86. doi: 10.1016/j.jaad.2014.02.038

Lyell, A., Gordon, A. M., Dick, H. M., and Sommerville, R. G. (1967). Mycoplasmas and erythema multiforme. Lancet 2, 1116-1118. doi: 10.1016/S01406736(67)90620-4

Matsuda, K., Narita, M., Sera, N., Maeda, E., Yoshitomi, H., Ohya, H., et al. (2013). Gene and cytokine profile analysis of macrolide-resistant Mycoplasma pneumoniae infection in Fukuoka, Japan. BMC Infect. Dis. 13:591. doi: 10.1186/1471-2334-13-591

Matsumoto, N., Takahashi, S., Toriumi, N., Sarashina, T., Makita, Y., Tachibana, Y., et al. (2009). Acute disseminated encephalomyelitis in an infant with incontinentia pigmenti. Brain Dev. 31, 625-628. doi: 10.1016/j.braindev.2008.08.010

Meseguer, M. A., de Rafael, L., and Vidal, M. L. (1986). Stevens-Johnson syndrome with isolation of Mycoplasma pneumoniae from skin lesions. Eur. J. Clin. Microbiol. 5, 167-168. doi: 10.1007/BF02013977

Mesraoua, B., Abbas, M., D’Souza, A., Miyares, F. R., Hashem, M., Osman, Y., et al. (2011). Adult opsoclonus-myoclonus syndrome following Mycoplasma pneumoniae infection with dramatic response to plasmapheresis. Acta Neurol. Belg. 111, 136-138.

Meyer Sauteur, P. M., Goetschel, P., and Lautenschlager, S. (2012). Mycoplasma pneumoniae and mucositis- part of the Stevens-Johnson syndrome spectrum. J. Dtsch. Dermatol. Ges. 10, 740-746. doi: 10.1111/j.1610-0387.2012.07951.x

Meyer Sauteur, P. M., Jacobs, B. C., Spuesens, E. B. M., Jacobs, E., Nadal, D., Vink, C., et al. (2014b). Antibody responses to Mycoplasma pneumoniae: role in pathogenesis and diagnosis of encephalitis? PLoS Pathog. 10:e1003983. doi: 10.1371/journal.ppat.1003983

Meyer Sauteur, P. M., Relly, C., Hackenberg, A., Stahr, N., Berger, C., Bloemberg, G. V., et al. (2014a). Mycoplasma pneumoniae intrathecal antibody responses in Bickerstaff brain stem encephalitis. Neuropediatrics 45, 61-63. doi: 10.1055/s0033-1348150

Miyashita, N., Kawai, Y., Inamura, N., Tanaka, T., Akaike, H., Teranishi, H., et al. (2015a). Setting a standard for the initiation of steroid therapy in refractory or severe Mycoplasma pneumoniae pneumonia in adolescents and adults. J. Infect. Chemother. 21, 153-160. doi: 10.1016/j.jiac.2014.10.008

Miyashita, N., Kawai, Y., Tanaka, T., Akaike, H., Teranishi, H., Wakabayashi, T. et al. (2015b). Diagnostic sensitivity of a rapid antigen test for the detection of Mycoplasma pneumoniae: comparison with real-time PCR. J. Infect. Chemother. 21, 473-475. doi: 10.1016/j.jiac.2015.02.007 
Nagashima, M., Higaki, T., Satoh, H., and Nakano, T. (2010). Cardiac thrombus associated with Mycoplasma pneumoniae infection. Interact. CardioVasc. Thorac. Surg. 11, 849-851. doi: 10.1510/icvts.2010.242115

Narita, M. (2002). Acute necrotizing encephalopathy by Mycoplasma pneumoniae infection? Arch. Intern. Med. 162:1647. doi: 10.1001/archinte.162.14.1647-a

Narita, M. (2009). Pathogenesis of neurologic manifestations of Mycoplasma pneumoniae infection. Pediatr. Neurol. 41, 159-166. doi: 10.1016/j.pediatrneurol.2009.04.012

Narita, M. (2010). Pathogenesis of extrapulmonary manifestations of Mycoplasma pneumoniae infection with special reference to pneumonia. J. Infect. Chemother. 16, 162-169. doi: 10.1007/s10156-010-0044-X

Narita, M. (2011a). "Mycoplasma pneumoniae as an under-recognized agent of vasculitic disorders," in Advances in the Etiology, Pathogenesis and Pathology of Vasculitis, ed L. M. Amezcua-Guerra (Rijeka: In Tech), 37-56. Available online at: http://www.intechopen.com/books/advances-in-the-etiologypathogenesis-and-pathology-of-vasculitis/mycoplasma-pneumoniae-as-anunder-recognized-agent-of-vasculitic-disorders

Narita, M. (2011b). Two unexpected phenomena in macrolide-resistant Mycoplasma pneumoniae infection in Japan and the unique biological characteristics of Mycoplasma pneumoniae. J. Infect. Chemother. 17, 735-736. doi: 10.1007/s10156-011-0235-0

Narita, M., Tanaka, H., Abe, S., Yamada, S., Kubota, M., and Togashi, T. (2000). Close association between pulmonary disease manifestation in Mycoplasma pneumoniae infection and enhanced local production of interleukin-18 in the lung, independent of gamma interferon. Clin. Diagn. Lab. Immunol. 7, 909-914. doi: $10.1128 /$ cdli.7.6.909-914.2000

Narita, M., Tanaka, H., Togashi, T., and Abe, S. (2005). Cytokines involved in CNS manifestations caused by Mycoplasma pneumoniae. Pediatr. Neurol. 33, 105-109. doi: 10.1016/j.pediatrneurol.2005.03.003

Norton, S. A. (2015). Diagnosing Mycoplasma pneumoniae-induced rash and mucositis (MIRM) in the emergency room. J. Am. Acad. Dermatol. 73, e67. doi: 10.1016/j.jaad.2015.03.060

Nunes, J. C., Bruscato, A. M., Walz, R., and Lin, K. (2011). Opsoclonus-myoclonus syndrome associated with Mycoplasma pneumoniae infection in an elderly patient. J. Neurol. Sci. 305, 147-148. doi: 10.1016/j.jns.2011.03.012

Ohya, H., Narita, M., Oda, Y., Furukawa, I., Watanabe, Y., Kuroki, T., et al. (2010). In vitro development of resistance to macrolides in Mycoplasma pneumoniae isolates, and transition mutation in 23SrRNA gene of the resistant strains. -the comparison of azithromycin and rokitamycin in selection of macrolide resistant M. pneumoniae. Jpn. J. Mycoplasmol. 37, 55-58.

Ohya, H., Narita, M., Suzuki, I., Watanabe, Y., Kuroki, T., and Okazaki, N. (2009). In vitro development of resistance to macrolides in Mycoplasma pneumoniae isolates, and transition mutation in 23SrRNA gene of the resistant strains. -the comparison of erythromycin and clarithromycin in selection of macrolide resistant M. pneumoniae. Jpn. J. Mycoplasmol. 36, 58-61.

Oishi, T., Narita, M., Matsui, K., Shirai, T., Matsuo, M., Negishi, J., et al. (2011). Clinical implications of interleukin-18 levels in pediatric patients with Mycoplasma pneumoniae pneumonia. J. Infect. Chemother. 17, 803-806. doi: 10.1007/s10156-011-0265-7

Oishi, T., Narita, M., Ohya, H., Yamanaka, T., Aizawa, Y., Matsuo, M., et al. (2012). Rhabdomyolysis associated with antimicrobial drug-resistant Mycoplasma pneumoniae. Emerg. Infect. Dis. 18, 849-851. doi: 10.3201/eid1805.111149

Okazaki, N., Narita, M., Yamada, S., Izumikawa, K., Umetsu, M., Kenri, T., et al. (2001). Characteristics of macrolide-resistant Mycoplasma pneumoniae strains isolated from patients and induced with erythromycin in vitro. Microbiol. Immunol. 45, 617-620. doi: 10.1111/j.1348-0421.2001.tb01293.x

Olson, D., Watkins, L. K. F., Demirjian, A., Lin, X., Robinson, C. C., Pretty, K., et al. (2015). Outbreak of Mycoplasma pneumoniae-associated Stevens-Johnson syndrome. Pediatrics 136, e386-e394. doi: 10.1542/peds.2015-0278

Pauchant, O., Ménard, A., Renaudin, H., Morozumi, M., Ubukata, K., and Bébéar, C. M. (2009). Increased macrolide resistance of Mycoplasma pneumoniae in France directly detected in clinical specimens by real-time PCR and melting curve analysis. J. Antimicrob. Chemother. 64, 52-58. doi: 10.1093/jac/ dkp160

Perez, C., Mendoza, H., Hernandez, R., Valcayo, A., and Guarch, R. (1997). Leukocytoclastic vasculitis and polyarthritis associated with Mycoplasma pneumoniae infection. Clin. Infect. Dis. 25, 154-155. doi: 10.1086/516888
Perez, C., and Montes, M. (2002). Cutaneous leukocytoclastic vasculitis and encephalitis associated with Mycoplasma pneumoniae infection. Arch. Intern. Med. 162, 352-354. doi: 10.1001/archinte.162.3.352

Petrone, B. L., Wolff, B. J., DeLaney, A. A., Diaz, M. H., and Winchell, J. M. (2015). Isothermal detection of Mycoplasma pneumoniae directly from respiratory clinical specimens. J. Clin. Microbiol. 53, 2970-2976. doi: 10.1128/JCM. 01431-15

Rhodes, R. H., Monastersky, B. T., Tyagi, R., and Coyne, T. (2011). Mycoplasmal cerebral vasculopathy in a lymphoma patient: presumptive evidence of Mycoplasma pneumoniae microvascular endothelial cell invasion in a brain biopsy. J. Neurol. Sci. 309, 18-25. doi: 10.1016/j.jns.2011.07.043

Schalock, P. C., and Dinulos, J. G. H. (2009). Mycoplasma pneumoniae-induced cutaneous disease. Int. J. Dermatol. 48, 673-681. doi: 10.1111/j.13654632.2009.04154.x

Schmucker, R. D., Ehret, A., and Marshall, G. S. (2014). Cerebellitis and acute obstructive hydrocephalus associated with Mycoplasma pneumoniae infection. Pediatr. Infect. Dis. J. 33, 529-532. doi: 10.1097/INF.0000000000 000140

Shen, Y., Zhang, J., Hu, Y., and Shen, K. (2013). Combination therapy with immune-modulators and moxifloxacin on Fulminant macrolide-resistant Mycoplasma pneumoniae infection: a case report. Pediatr. Pulmonol. 48, 519-522. doi: 10.1002/ppul.22650

Shibuya, H., Osamura, K., Hara, K., and Hisada, T. (2012). Clinically mild encephalitis/encephalopathy with a reversible splenial lesion due to Mycoplasma pneumoniae infection. Intern. Med. 51, 1647-1648. doi: 10.2169/internalmedicine.51.7676

Shiihara, T., and Takahashi, Y. (2010). Correspondence: a further case of opsoclonus-myoclonus syndrome associated with Mycoplasma pneumoniae infection. Eur. J. Pediatr. 169, 639. doi: 10.1007/s00431-009$1105-\mathrm{y}$

Shimizu, M., Hamaguchi, Y., Matsushita, T., Sakakibara, Y., and Yachie, A. (2012). Sequentially appearing erythema nodosum, erythema multiforme and HenochSchönlein purpura in a patient with Mycoplasma pneumoniae infection: a case report. J. Med. Case Rep. 6:398. doi: 10.1186/1752-1947-6-398

Shin, S. R., Park, S. H., Kim, J.-H., Ha, J.-W., Kim, Y. J., Jung, S. W., et al. (2012). Clinical characteristics of patients with Mycoplasma pneumoniae-related acute hepatitis. Digestion 86, 302-308. doi: 10.1159/000341401

Shkalim, V., Amir, J., Kornreich, L., Scheuerman, O., and Straussberg, R. (2009). Acute cerebellitis presenting as tonsillar herniation and hydrocephalus. Pediatr. Neurol. 41, 200-203. doi: 10.1016/j.pediatrneurol.2009.04.024

Simpkins, A., Strickland, S. M., Oliver, J., Murray, D. L., Steele, J. C. H., Park, Y. D., et al. (2012). Complete resolution of advanced Mycoplasma pneumoniae encephalitis mimicking brain mass lesions: report of two pediatric cases and review of literature. Neuropathology 32, 91-99. doi: 10.1111/j.14401789.2011.01225.x

Stamm, B., Moschopulos, M., Hungerbuehler, H., Guarner, J., Genrich, G. L., and Zaki, S. R. (2008). Neuroinvasion by Mycoplasma pneumoniae in acute disseminated encephalomyelitis. Emerg. Infect. Dis. 14, 641-643. doi: 10.3201/eid1404.061366

Sterner, G., and Biberfeld, G. (1969). Central nervous system complications of Mycoplasma pneumoniae infection. Scand. J. Infect. Dis. 1 , 203-208.

Tanaka, H., Narita, M., Teramoto, S., Saikai, T., Oashi, K., Igarashi, T., et al. (2002). Role of interleukin-18 and T-helper type 1 cytokines in the development of Mycoplasma pneumoniae pneumonia in adults. Chest 121, 1493-1497. doi: 10.1378/chest.121.5.1493

Tay, C. G., Fong, C. Y., and Ong, L. C. (2014). Transient Parkinsonism following Mycoplasma pneumoniae infection with normal brain magnetic resonance imaging (MRI). J. Child Neurol. 29, NP193-NP195. doi: $10.1177 / 0883073813510741$

Terraneo, L., Lava, S. A. G., Camozzi, P., Zgraggen, L., Simonetti, G. D., Bianchetti, M. G., et al. (2015). Unusual eruptions associated with Mycoplasma pneumoniae respiratory infections: review of the literature. Dermatology 231, 152-157. doi: 10.1159/000430809

Trčko, K., Marko, P. B., and Miljković, J. (2012). Leukocytoclastic vasculitis induced by Mycoplasma pneumoniae infection. Acta Dermatovenerol. Croat. 20, $118-121$. 
Van Bever, H. P., Van Doorn, J. W. D., and Demey, H. E. (1992). Adult respiratory distress syndrome associated with Mycoplasma pneumoniae infection. Eur. J. Pediatr. 151, 227-228. doi: 10.1007/BF019 54392

Vitale, E. A., La Torre, F., Calcagno, G., Infricciori, G., Fede, C., Conti, G., et al. (2010). Mycoplasma pneumoniae: a possible trigger of Kawasaki disease or a mere coincidental association? Report of the first four Italian cases. Minerva Pediatr. 62, 605-607.

Vujic, I., Shroff, A., Grzelka, M., Posch, C., Monshi, B., Sanlorenzo, M., et al. (2015). Mycoplasma pneumoniae-associated mucositis-case report and systematic review of literature. J. Eur. Acad. Dermatol. Venereol. 29, 595-598. doi: $10.1111 /$ jdv. 12392

Wetter, D. A., and Camilleri, M. J. (2010). Clinical etiologic, and histopathologic features of Stevens-Johnson syndrome during an 8-year period at Mayo clinic. Mayo Clin. Proc. 85, 131-138. doi: 10.4065/mcp.2009.0379

Yang, A., Kang, B., Choi, S. Y., Cho, J. B., Kim, Y.-J., Jeon, T. Y., et al. (2015). Acute necrotizing pancreatitis associated with Mycoplasma pneumoniae infection in a child. Pediatr. Gastroenterol. Hepatol. Nutr. 18, 209-215. doi: 10.5223/pghn.2015.18.3.209

Yuan, Z.-F., Chen, B., Mao, S.-S., Shen, J., Yu, Y.-L., Gao, F., et al. (2015). Reversible bilateral striatal lesions following Mycoplasma pneumoniae infection associated with elevated levels of interleukins 6 and 8. Brain Dev. 38, 149-153. doi 10.1016/j.braindev.2015.04.008

Zhou, Y., Zhang, Y., Sheng, Y., Zhang, L., Shen, Z., and Chen, Z. (2014). More complications occur in macrolide-resistant than in macrolide-sensitive Mycoplasma pneumoniae pneumonia. Antimicrob. Agents Chemother. 58, 1034-1038. doi: 10.1128/AAC.01806-13

Zu-Rhein, G. M., Lo, S.-C., Hulette, C. M., and Powers, J. M. (2007). A novel cerebral microangiopathy with endothelial cell atypia and multifocal white matter lesions: a direct mycoplasmal infection? J. Neuropathol. Exp. Neurol. 66, 1100-1117. doi: 10.1097/NEN.0b013e31815c1e09

Conflict of Interest Statement: The author declares that the research was conducted in the absence of any commercial or financial relationships that could be construed as a potential conflict of interest.

Copyright $(\odot 2016$ Narita. This is an open-access article distributed under the terms of the Creative Commons Attribution License (CC BY). The use, distribution or reproduction in other forums is permitted, provided the original author(s) or licensor are credited and that the original publication in this journal is cited, in accordance with accepted academic practice. No use, distribution or reproduction is permitted which does not comply with these terms. 